\title{
METHOD FOR ASSESSMENT OF CHANGES IN THE WIDTH OF CRACKS IN CEMENT COMPOSITES WITH USE OF COMPUTER IMAGE PROCESSING AND ANALYSIS
}

\author{
KAMIL TOMCZAK, JACEK JAKUBOWSKI, PRZEMYSŁAW FIOŁEK \\ AGH University of Science and Technology, Department of Geomechanics, \\ Civil Engineering and Geotechnics, e-mail: jakubjac@agh.edu.pl
}

\begin{abstract}
Crack width measurement is an important element of research on the progress of self-healing cement composites. Due to the nature of this research, the method of measuring the width of cracks and their changes over time must meet specific requirements. The article presents a novel method of measuring crack width based on images from a scanner with an optical resolution of $6400 \mathrm{dpi}$, subject to initial image processing in the ImageJ development environment and further processing and analysis of results. After registering a series of images of the cracks at different times using SIFT conversion (Scale-Invariant Feature Transform), a dense network of line segments is created in all images, intersecting the cracks perpendicular to the local axes. Along these line segments, brightness profiles are extracted, which are the basis for determination of crack width. The distribution and rotation of the line of intersection in a regular layout, automation of transformations, management of images and profiles of brightness, and data analysis to determine the width of cracks and their changes over time are made automatically by own code in the ImageJ and VBA environment. The article describes the method, tests on its properties, sources of measurement uncertainty. It also presents an example of application of the method in research on autogenous self-healing of concrete, specifically the ability to reduce a sample crack width and its full closure within 28 days of the self-healing process.
\end{abstract}

Key words: cracks in concrete, crack width measurement, image processing, self-healing

\section{INTRODUCTION}

Computer processing and image analysis is widely used in various fields of science and technology. Examples are studies that require quantification of any defects on the surface of the material in the form of cracks, cavities or chipped surface (Glinicki and Litorowicz [2]; Szeląg and Fic [7]). A special case is the study of the self-healing process of cement matrix composites in which a reduction in the width of cracks, observed at different points in time, is due to the formation of defects on the surface of products of the self-healing process (Huang et al. [3]). The advantage of these test methods is the possibility of repeated observations of the surface areas relevant to research and documentation purposes, in the form of high-resolution pictures with different types of cameras (Kanellopoulos et al. [5]; Wang et al. [8]) or scanners using CCD matrices. Digital recording of image of the surface is the basis for further processing and analysis using computer methods. Despite the prevalence of practical use of image metrology, there are no universal solutions to automate the measurement of changes on the surfaces of the self-healing materials that have only recently been of interest to materials science.

The purpose of this article is to present novel algorithms for detecting cracks in high resolution images and identifying geometric features of cracks and their changes, especially changes in crack width. The procedures created were to deliver results of repeatable parameters, independent of subjective values entered by the user as is the case in threshold computing methods. Image pre-processing and preparation for analysis involved the ImageJ development environment (Abramoff et al. [1]). Further extraction and analysis of marked data required complex procedures custom-programmed in VBA.

\section{DESCRIPTION OF THE METHOD FOR MEASURING CRACK WIDTH}

The method is adapted for examining changes in crack width on the surfaces of small-size concrete samples of any geometry, for example, cylindrical samples $\varnothing 100 \times 200$ and $\varnothing 150 \times 300 \mathrm{~mm}$ made from different concrete mixtures, which shall examine the 
micro-cracks with a width from 50 to about $800 \mu \mathrm{m}$. Perpetuating the image of the surface of the samples involves the Epson V600 scanner with the optical resolution of 6400 dpi equipped with a CCD matrix. With a constant distance between the image recorder and the scanned surface, and the fixed resolution of the scanner, surface images feature the same scale. The resolution of the raw data to be analyzed is not greater than the size of one pixel, or about $4.0 \mu \mathrm{m}$.

The first stage of the algorithm involves image processing and analysis, carried out in the Image $\mathrm{J} 1.51 \mathrm{~g}$ environment, using the created macros. To improve the operations on the digital image library, photos of the same areas of sample surface are collected in a chronologically ordered stack of images. Due to the large size of images in an RGB palette with 24 bit color depth, the created stacks occupy more than 1GB of mass memory space, which often requires splitting images into smaller parts in the case of limited computing capacity. In order to transfer the resulting set of images to a single coordinate system (the coordinate systems of every first image in the stacks), it is subjected to a registration process (in other words, adjustment) using the SIFT method (Scale Invariant Feature Transformation) (Lowe [4]). This method used, e.g., in searching model objects in images or characteristic points for the purpose of combining aerial photos (Pawlik and Mikrut [6]), is one of the methods for the detection of stable local characteristics. In the SIFT method, characteristic points common to any pair of images are searched on the basis of a pyramid of images of ever-decreasing resolutions. To put it more precisely, the images that make up a pyramid are differentials arising after subtracting the two images of the initial filtered Gaussian filters with different $\sigma$ parameters. After further transformations in the so-called octaves of images with the same resolution and different Gaussian filters, local characteristics are identified as local minima and maxima in the images of the pyramid. The located points must be characterized by a brightness exceeding a given threshold and cannot lie along a straight line. The designated points, which have a calculated feature vector in the form of gradient histograms in their environment, constitute the basis for the search for common points between images.

Adjusting the coordinate system of the image stack to the first photo is done by implementing the SIFT method in the ImageJ environment using the recommended values of input variables (Table 1). Due to the characteristics of the image formed during the scan, free of local and global angular deformations, the expected image transformations while processing with the selected method are "rigid" transformations.

Table 1. Set of recommended input parameter values for adjusting the images using the SIFT method in ImageJ

\begin{tabular}{|l|c|}
\hline \multicolumn{2}{|c|}{ Scale invariant interest point detector } \\
\hline Initial Gaussian blur & 1.6 pixels \\
\hline Steps per scale octave & 3 \\
\hline Minimum image size & 64 pixels \\
\hline Maximum image size & 1024 pixels \\
\hline \multicolumn{2}{|c|}{ Feature descriptor } \\
\hline Feature descriptor size & 4 \\
\hline Feature descriptor orientation bins & 8 \\
\hline Closest/next closest ratio & 0.92 \\
\hline \multicolumn{2}{|c|}{ Geometric consensus filter } \\
\hline Maximal alignment error & 25 pixels \\
\hline Inlier ratio & 0.05 \\
\hline Expected transformation & rigid \\
\hline Output interpolation & yes \\
\hline
\end{tabular}

The prepared image stacks in tiff are subjected to the algorithm ensuring the location of the surface of cracks due to searching for areas of minimal brightness corresponding to the black color. Along this line object, a regular array of lines is generated automatically, at predetermined intervals between the lines (100 pixels), which intersect the local symmetry axis of the crack at a straight angle (Fig. 1).

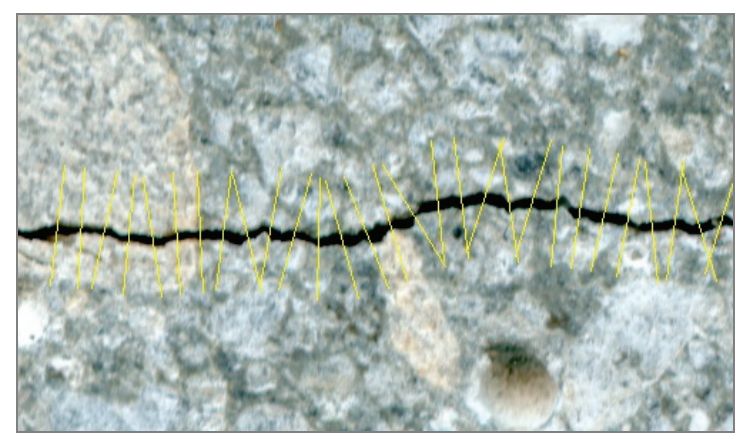

Fig. 1. Section of an image with intersection lines on the crack of average width $160 \mu \mathrm{m}$

The grid of intersection lines with one coordinate system in the stack is located on all images at the same point. This arrangement makes it possible to extract sets of values along the intersection lines, representing the brightness of the elements of the database analyzed in the next step.

The analysis of data in the database is based on observations which are illustrated in Fig. 2. The image area of the sample surface, identical to the inner part 




a)

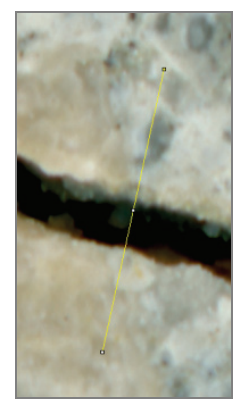

b)

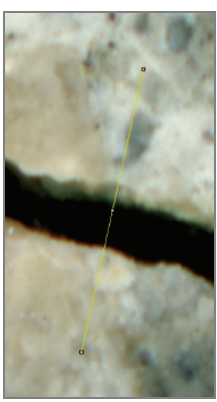

c)

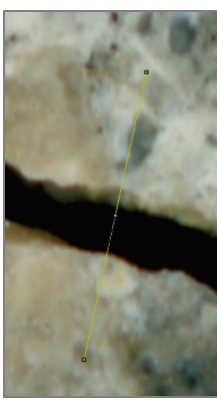

d)

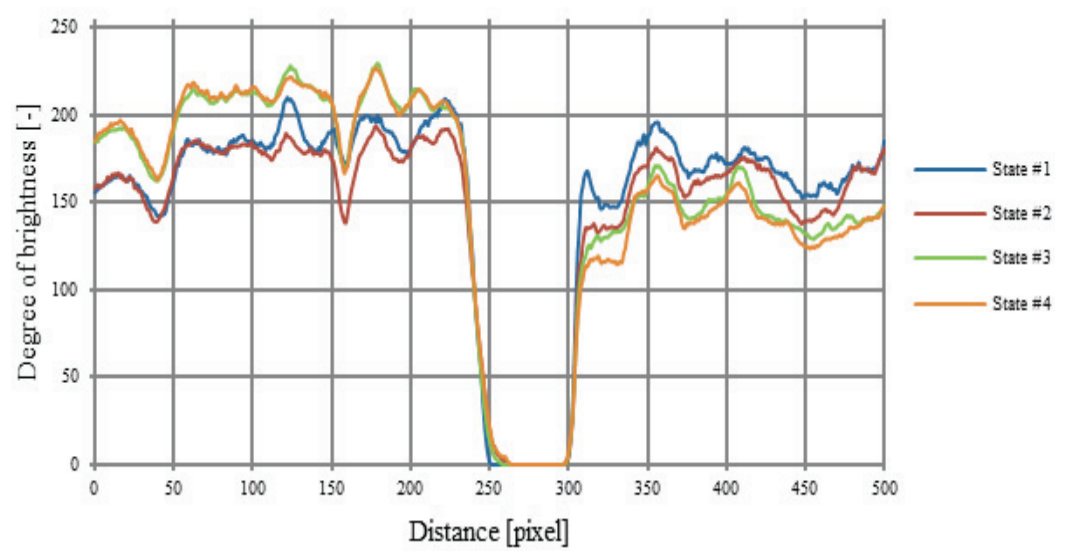

Fig. 2. The image of the sample surface with a crack and an intersection line in four different states of water saturation, and the sample position on the scanner during the scanning (a-d) and graphs of brightness along the line of intersection

of the crack in the material structure is presented in the graph showing dependence of brightness degrees of points along the intersection line and the position on the line as a global minimum. Another characteristic is that the points of intersection of the surface discontinuity with the sample surface to be scanned upon the same graph are located in close proximity to the first local maxima on both sides of the global minimum. New local maxima are formed in the image due to the refraction of the scanner light rays by material refractions on both sides of the discontinuities.

Two different definitions were initially proposed and tested, as well as their two corresponding algorithms based on which crack widths are determined in the area of the intersection line. The first one (DEF1) is based on the observation that around the edge of the crack there are local maxima on the graph of brightness along the line of intersection. The definition states that crack width extends between the first two local maxima on both sides of the crack in the brightness level graph. In this case, width is equal to the difference of the position coordinates on the intersection line for the values of the maxima. In the second definition (DEF2) the crack width equals the distance between the points in the graph of brightness degree, for which the inclination of the graph is the greatest.
Thus, the boundaries of the crack are placed where the degree of brightness from a local minimum to two local maxima on its both sides is growing the fastest.

The occurrence of changes on the surface of discontinuities due to the self-healing process, in which cavities are being filled in observed to be, typically brightly colored, results in changes in the brightness of the graphs in relation to the initial state. Typically, these changes are imaged through the increase of the local maxima on both sides of the global minimum graph for incomplete crack closure. However, in cases where structural integrity of the material is restored, the maximum appears near the initial occurrence of the global minimum in the graph, sometimes a global maximum in the graph of brightness degree. Therefore, for the rest of the images except for the first in the stack, the algorithm provides for the execution of a set of conditional statements before proceeding to determine the width using both definitions. Analyzing the shape of the curves, these instructions check whether within the range for the position between the local maxima in the first image, there is a state indicating the restoration of the integrity of the material. In this case, the crack width value being determined reaches 0 . In other cases, the next step involves calculating the crack width in 
accordance with the definitions and using the newly designated local extremes.

\section{ESTIMATION OF MEASUREMENT UNCERTAINTY}

Due to the fact that the object of research is a composite porous material with water absorption capacity, the differences between the humidity of the sample manifest themselves in uneven changes in brightness levels in different areas. Furthermore, it is impossible to position the sample identically on the scanner when scanning the surface at different time points, resulting in the possibility of illumination angle of the area inside the discontinuity being different. Some erroneous crack width measurements can also be caused by local artifacts on the scanned and processed images of the surface.

Therefore, to evaluate the uncertainty of the method, two series of measurements were conducted. Scans were carried out in a short period of time in order to eliminate the possibility of changes in the structure of the material caused by progression of the selfhealing process or washing out of the material. Both series were performed on a sample prepared from concrete mix M1_0.28 (Table 2). Scanning a sample area measuring $25 \times 75 \mathrm{~mm}$ was conducted directly after the cracking process and pre-drying the surface samples at $24 \pm 2{ }^{\circ} \mathrm{C}$ in relative humidity of $60 \pm 5 \%$.

In Test 1 , the scanning covered a sample with 12 different angles of rotation and translations in relation to the scanner plate. In Test 2, the scanning covered a sample with 6 visually apparent changes in water saturation on the surface of the material, while respecting the need to maintain the same position relative to the scanner plate. Both tests were to provide information for estimation of the uncertainty of the proposed methods for determining the crack width. Testing the impact of different rotations and translation of the sample with respect to the scanner's plate to determine crack width was conducted on a sample of $N=189$ intersection lines in $M=12$ different states. The test on the effect of different water saturation levels of the sample surface on the marked crack width was conducted on a sample of $N=276$ intersec-

Table 2. Composition of concrete mixtures $\left[\mathrm{kg} / \mathrm{m}^{3}\right]$

\begin{tabular}{|l|c|c|}
\hline \multicolumn{1}{|c|}{ Mix ingredients } & M1_0.28 & M2_0.23 \\
\hline cement CEM I 42,5R & 626 & 823 \\
\hline sand 0-2 mm & 658 & 576 \\
\hline dolomite aggregate $2-8 \mathrm{~mm}$ & 1117 & 979 \\
\hline water & 157 & 165 \\
\hline SP $\left(3 \% \mathrm{~m}_{\text {binder }}\right)-$ CHRYSO $^{\circledR}$ Fluid Optima 185 & 19 & 25 \\
\hline w/c & 0.28 & 0.23 \\
\hline
\end{tabular}

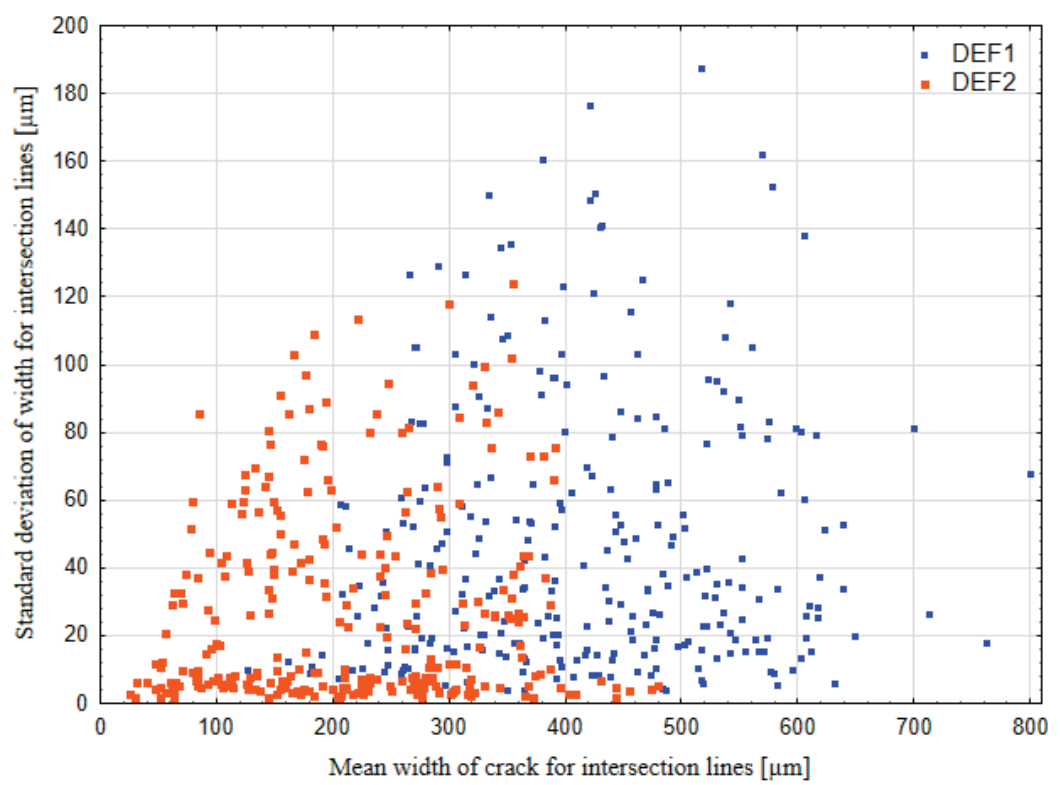

Fig. 3. Standard deviations of the width of crack for intersection lines measured with both definitions in TEST1 


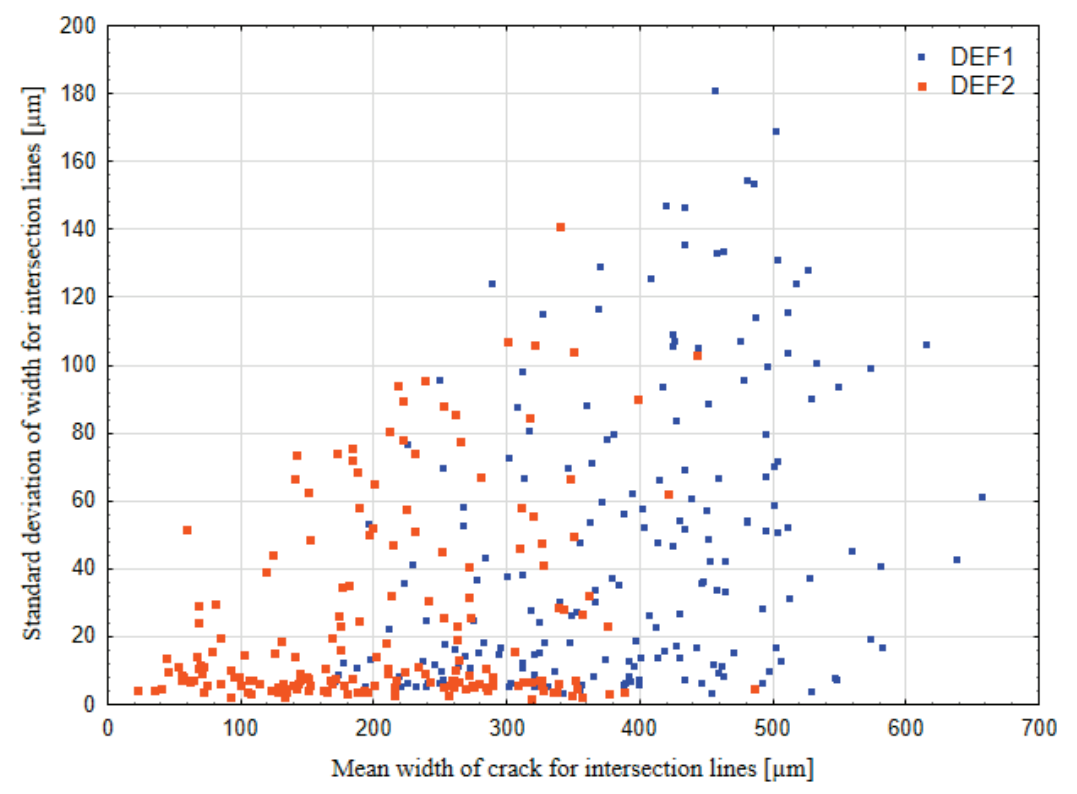

Fig. 4. Standard deviations of the width of crack measured with both width definitions in TEST2

tion lines in $M=6$ different states. For each intersection line $M$, the width of crack measurements was determined in accordance with DEF1 and DEF2. Mean and standard deviation of crack width were designated. The dependence of standard deviation the mean width in the dataset for each defined crack width and the two tests are illustrated graphically in Figs. 3 and 4.

Except for very narrow cracks, measurement errors do not depend on the crack width. Widths measured for each line of intersection in the $M$ element samples have symmetrical distributions with respect to the mean. For a single line of intersection $\bar{x}_{i}$ is the mean crack width in an $M$ element sample and $s_{i}$ is the standard deviation (Eqs. (1) and (2)). On the surface of the sample, there are $N$ lines of intersection and $N$ standard deviations are calculated. Let $s_{\text {int }}$ be the squared mean of these $N$ values (Eq. (3)).

$$
\begin{gathered}
\bar{x}_{i}=\frac{1}{M} \sum_{j=1}^{M} x_{i j}, \quad i=1, \ldots, N, \\
s_{i}^{2}=\frac{1}{M-1} \sum_{j=1}^{M}\left(x_{i j}-\bar{x}_{i}\right)^{2}, \quad i=1, \ldots, N, \\
s_{\text {int }}=\sqrt{\frac{1}{N} \sum_{i=1}^{N} s_{i}^{2} .}
\end{gathered}
$$

Empirical distributions of deviations from the mean of the $M$ measurements for all $N$ lines of intersection ( $M \cdot N$ deviations) for the measurement series TEST1 and TEST2 and both definitions DEF1 and DEF2 were examined. All distributions have large positive kurtosis. Squared mean of $s_{i}$ values gives an inflated estimate $s_{\text {int. }}$ As a result, the double-sided interval $\pm s_{\text {int }}$ is wide and contains as much as $92 \%$ of measurements. For TEST1 and TEST2 measurement series calculated values are denoted $s_{\text {int }}^{\text {TEST1 }}$ and $s_{\text {int }}^{\text {TEST2 }}$, respectively.

The procedure for determining the uncertainty of a crack width measurement on a single line intersection was described above. The key parameter is, however, the mean crack width $\bar{x}_{\text {sur }}$ across the sample surface (Eq. (5)) and the uncertainty of its measurement $s_{\text {sur }}$. For estimating this uncertainty mean crack width $\bar{x}_{j}$ for each of the $M$ states is calculated (Eq. (4)). Then the standard deviation $s_{\text {sur }}$ from these $M$ values is obtained (Eq. (6)).

$$
\begin{gathered}
\bar{x}_{j}=\frac{1}{N} \sum_{i=1}^{N} x_{i j}, \quad i=1, \ldots, M, \\
\bar{x}_{\text {sur }}=\frac{1}{M} \sum_{j=1}^{M} \bar{x}_{j}, \\
s_{\text {sur }}=\sqrt{\frac{1}{M-1} \sum_{j=1}^{M}\left(\bar{x}_{j}-\bar{x}_{\text {sur }}\right)^{2} .}
\end{gathered}
$$

It was assumed that $s_{\text {sur }}$ is the standard uncertainty of the mean crack width on the surface. For TEST1 and TEST2 measurement series respective values are denoted $s_{\text {sur }}^{\mathrm{TEST} 1}$ and $s_{\text {sur }}^{\mathrm{TEST} 2}$.

In the TEST1 series, the effect of changes in the position and orientation of the samples during the scan and in a TEST2 series the impact of various surface 
Table 3. Standard uncertainty of the measurements and the method

\begin{tabular}{|c|c|c|c|c|c|c|}
\cline { 2 - 7 } \multicolumn{1}{c|}{} & \multicolumn{2}{c|}{$\begin{array}{c}\text { TEST1 } \\
\text { Uncertainty } \\
\text { of measurement }\end{array}$} & \multicolumn{2}{c|}{$\begin{array}{c}\text { TEST2 } \\
\text { Uncertainty } \\
\text { of measurement }\end{array}$} & \multicolumn{2}{c|}{$\begin{array}{c}\text { Uncertainty } \\
\text { of the method }\end{array}$} \\
\cline { 2 - 7 } & $\begin{array}{c}\text { Width on } \\
\text { a single line } \\
\text { of intersection }\end{array}$ & $\begin{array}{c}\text { Average } \\
\text { width } \\
\text { across } \\
\text { the surface }\end{array}$ & $\begin{array}{c}\text { Width on } \\
\text { a single line } \\
\text { of intersection }\end{array}$ & $\begin{array}{c}\text { Average } \\
\text { width } \\
\text { across } \\
\text { the surface }\end{array}$ & $\begin{array}{c}\text { Width } \\
\text { measurement } \\
\text { on a line } \\
\text { of intersection }\end{array}$ & $\begin{array}{c}\text { Average } \\
\text { width } \\
\text { measurement } \\
\text { across } \\
\text { the surface }\end{array}$ \\
\cline { 2 - 7 } & $s_{\text {int }}^{\text {TEST1 }}$ & $s_{\text {sur }}^{\text {TEST1 }}$ & $s_{\text {int }}^{\text {TEST2 }}$ & $s_{\text {sur }}^{\text {TEST2 }}$ & $u_{\text {int }}$ & $u_{\text {sur }}$ \\
\hline DEF1 & 63.2 & $16 \mathrm{~m}]$ & {$[\mu \mathrm{m}]$} & {$[\mu \mathrm{m}]$} & {$[\mu \mathrm{m}]$} & {$[\mu \mathrm{m}]$} \\
\hline DEF2 & 37.6 & 4.3 & 40.0 & 6.4 & 54.9 & 20.1 \\
\hline
\end{tabular}

moistures of samples on variability of measured values were examined. It is judged that these are two independent sources of measurement errors. Therefore, the standard uncertainty of the crack width measurement on a single line of intersection $u_{\text {int }}$ (Eq. (7)) and the average crack width on the surface $u_{\text {sur }}$ (Eq. (8)) is calculated by combining those sources

$$
\begin{aligned}
& u_{\mathrm{int}}=\sqrt{\left(s_{\mathrm{int}}^{\mathrm{TEST} 1}\right)^{2}+\left(s_{\mathrm{int}}^{\mathrm{TEST} 2}\right)^{2}}, \\
& u_{\text {sur }}=\sqrt{\left(s_{\text {sur }}^{\mathrm{TEST1} 1}\right)^{2}+\left(s_{\text {sur }}^{\mathrm{TEST} 2}\right)^{2}} .
\end{aligned}
$$

The method will be used under similar conditions the study was conducted in TEST1 and TEST2 series of measurements. These values estimate uncertainty of the method of crack width measurement on a line of intersection $\left(u_{\mathrm{int}}\right)$ and the average crack width on the surface of a sample $\left(u_{\text {sur }}\right)$.

Besides estimating the uncertainty of width measurement, TEST1 and TEST2 measurement series allow for comparison of both definitions and algorithms for estimating the crack width. Due to greater robustness and lesser uncertainty of measurements (Table 3), DEF2 was selected and corresponding algorithm is accepted as the basic algorithm of the method.

\section{EXAMPLE OF APPLICATION}

The developed and tested algorithm was used for measuring crack width on a $\varnothing 100 \times 50 \mathrm{~mm}$ sample

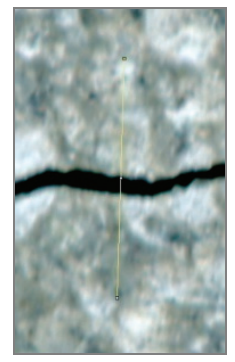

a)

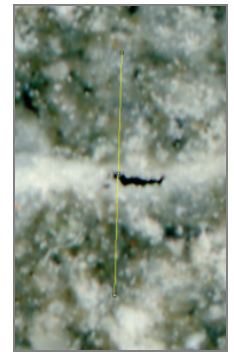

b)

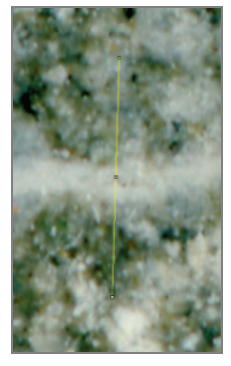

c)

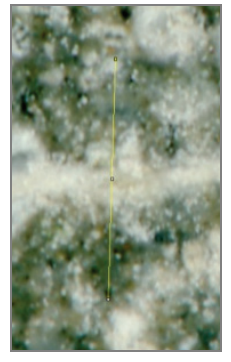

d)

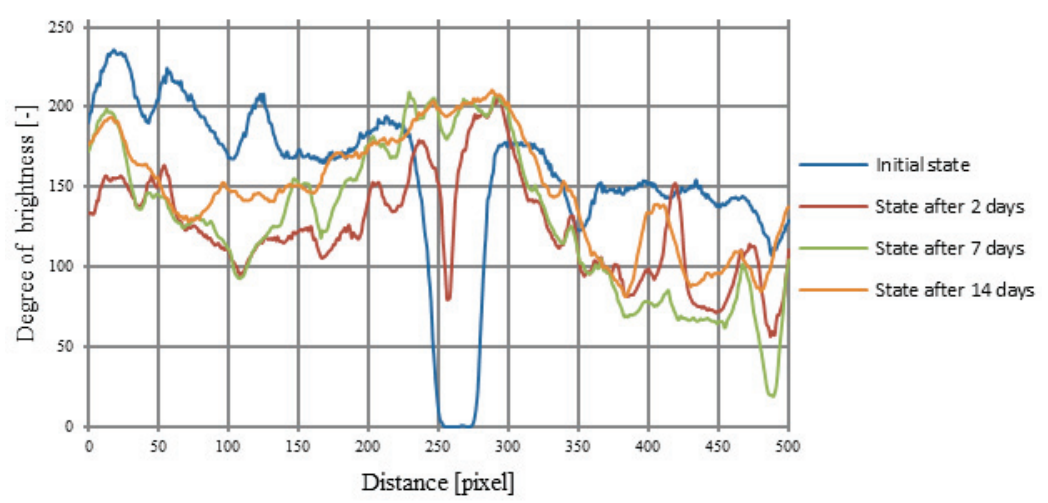

Fig. 5. Image of the sample surface with a crack and an intersection line: (a) immediately after cracking, (b) after 2, (c) 7 and (d) 14 days of self-healing and graphs of the brightness degree along the intersection line 
made of concrete M2_0.23 (Table 2). After the controlled cracking, the sample was stored and scanned in the same manner as the sample used to evaluate the method.
Figure 5 shows the recorded changes on the sample surface as a result of the self-healing progression and the graphs of brightness degrees at in points along the intersection line, which reflect these changes.

Table 4. Summary data on changes in crack width at different time points

\begin{tabular}{|l|c|c|c|c|c|}
\cline { 2 - 6 } \multicolumn{1}{c|}{} & \multicolumn{5}{c|}{ Scanning time points } \\
\cline { 2 - 6 } \multicolumn{1}{c|}{} & 0 days & +2 days & +4 days & +14 days & +28 days \\
\hline $\begin{array}{l}\text { Average crack width } \\
\text { across the surface }[\mu \mathrm{m}]\end{array}$ & 111 & 65 & 66 & 60 & 56 \\
\hline $\begin{array}{l}\text { Change in the average } \\
\text { crack width }[\mu \mathrm{m}]\end{array}$ & - & -46 & 0 & -4 & -4 \\
\hline $\begin{array}{l}\text { Number of intersection } \\
\text { lines with a full crack } \\
\text { closure }(\% \text { of the total) }\end{array}$ & $\begin{array}{c}0 \%) \\
(0 \%)\end{array}$ & $\begin{array}{c}45 \\
(29 \%)\end{array}$ & $\begin{array}{c}50 \\
(32 \%)\end{array}$ & $\begin{array}{c}56 \\
(36 \%)\end{array}$ & $\begin{array}{c}55 \\
(35 \%)\end{array}$ \\
\hline
\end{tabular}

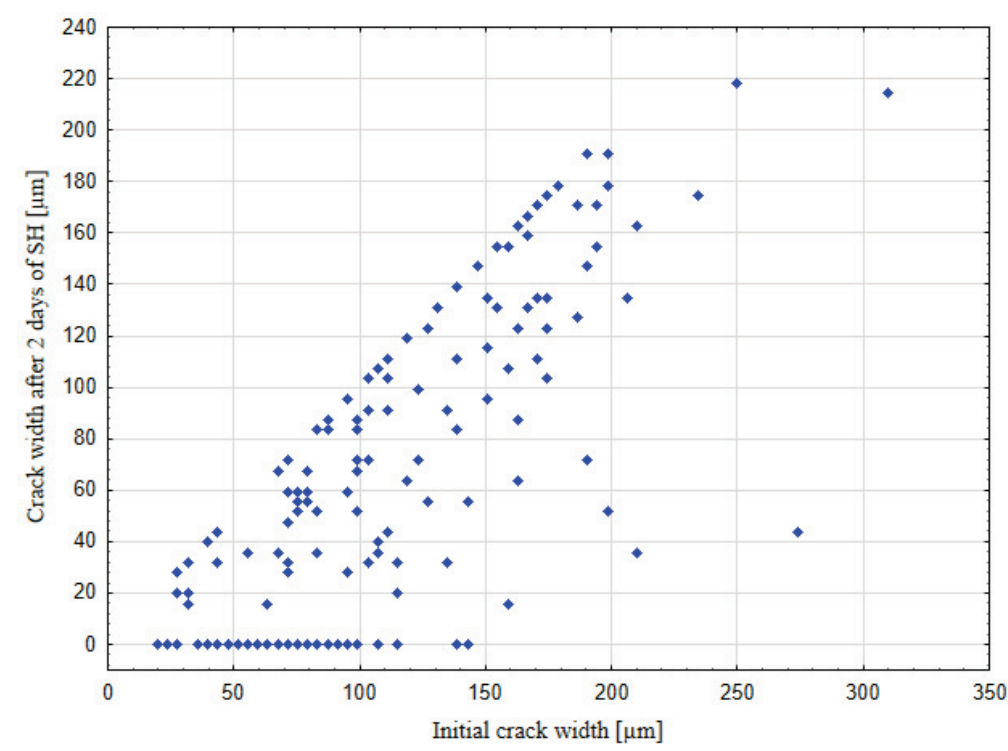

Fig. 6. Crack width on intersection lines after 2 days of self-healing process, compared to the initial crack width

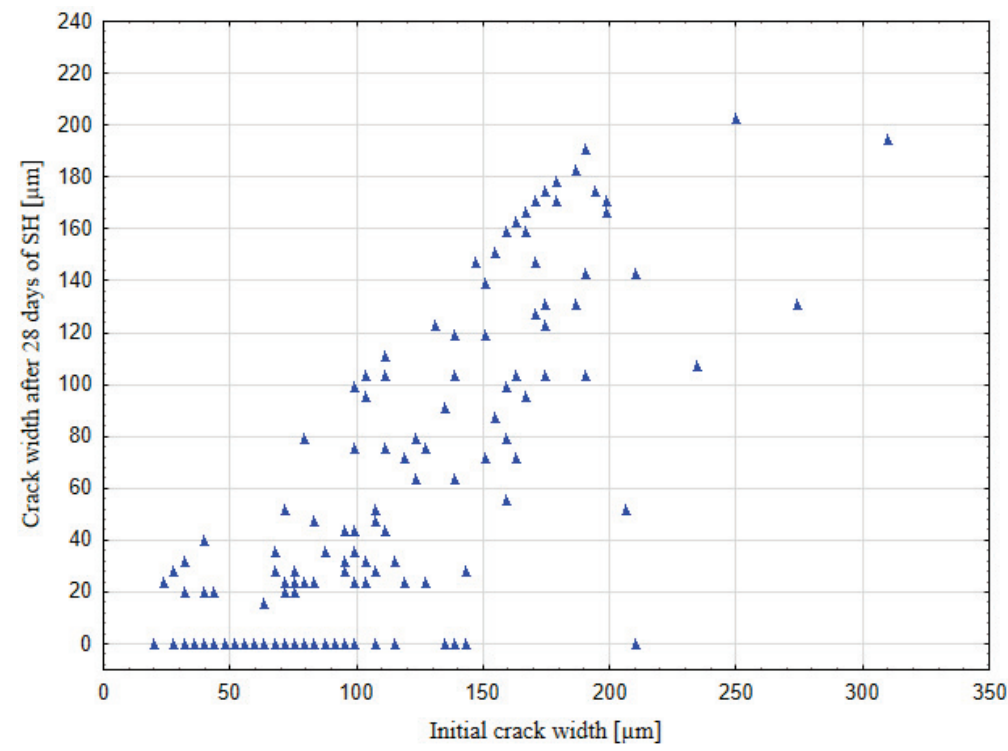

Fig. 7. Crack width on intersection lines after 28 days of self-healing process, compared to the initial crack width 
Measurement results describing the autogenous self-healing process of the cement composite are shown in Table 4. Measurement effective resolution is limited by standard measurement uncertainty and pixel dimension.

A substantial part of the self-healing process progressed in the first two days. At the subsequent time points much slower progression of self-healing was observed, characterized by very small average crack width decrease, less than standard measurement uncertainty. Observations with an electronic microscope and the measurements made on the images of other scanned surfaces show that the effects of the selfhealing process may be temporary and reversible in some circumstances.

The data in Figs. 6 and 7 confirm that the self-healing progress depends on the initial crack width. The decline in average crack width is accompanied by an increase in the amount of line of intersection with a full crack closure. The maximum width, at which a full crack closure was registered, is $210 \mu \mathrm{m}$ and was reached after 28 days of self-healing. $88 \%$ of the intersection lines showed a reduction in crack width, while the full crack closure occurred in over $35 \%$ of cases.

\section{SUMMARY}

Semi-automated measurements of crack width changes in subsequent time steps are necessary to investigate the process of self-healing cement composites. A method for crack width measurement based on high-resolution scanning was proposed. The method uses SIFT transform, development environment ImageJ, novel algorithms and programs to automate the process and analysis of the results. The properties of the method, particularly two major sources of measurement errors were examined. The estimated standard uncertainty of average crack width over the sample surface measurement is $\pm 8 \mu \mathrm{m}$. Further investigations on sources of uncertainty might be desirable, particularly if crack width measurements for single intersection lines are used.

The presented algorithm allows data to be obtained that is useful in assessing the progress and nature of the self-healing process in the composites under study with cement matrix. Further detailed research on correlations between the variables associated with the components of the concrete mix and efficiency of that process may lead to concrete durability improvement. To perform this, much greater quantity and diversity of concrete samples will be needed, as well as the automation of tedious procedures for image processing and data analysis, provided by the macrocommands created.

The advantage of the test method proposed lies in the possibility of using images obtained via other types of recorders, including microscopes with digital image recording. The use of portable digital image recorders will help solve the basic problem of the dimensions of the scanned concrete sample being limited to the size of the scanner's plate. However, in this case, it is important to ensure constant illumination during each test and angle, at which the image recording system is set towards the recorded surface. To some extent, the proposed algorithm of image registration is resistant to deformation angle due to the use of the SIFT method. However, large angular distortions in images may lead to an increase in the error of the method. In the case of adapting the method or significant changes in use conditions, additional preliminary tests for evaluation of measurement uncertainty are necessary.

\section{ACKNOWLEDGEMENTS}

Prepared for the AGH UST research project 11.11.100.197.

\section{REFERENCES}

[1] Abramoff M.D., Magalhaes P.J., Ram S.J., Image Processing with ImageJ, Biophotonics International, 2004, 11 (7), 36-42.

[2] Glinicki M.A., Litorowicz A., Diagnostyka rys w kompozytach o matrycy cementowej metoda komputerowej analizy obrazu, Drogi i Mosty, 2007, 3, 45-77.

[3] Huang H., Ye G., Qian C., Schlangen E., Self-healing in cementitious materials: Materials, methods and service conditions, Materials and Design, 2016, 92, 499-511.

[4] Lowe D.G., Distinctive image features from scale-invariant keypoints, International Journal of Computer Vision, 2004, 60 (2), 91-110.

[5] Kanellopoulos A., Qureshi T.S., Al-TabBaA A., Glass encapsulated minerals for self-healing in cement based composites, Construction and Building Materials, 2015, 98, 780-791.

[6] Pawlik P., Mikrut S., Wyszukiwanie punktów charakterystycznych na potrzeby zdjęć lotniczych, Automatyka, 2006, 10 (3), 407-411.

[7] SzELĄG M., FIC S., Analiza rozwoju spękań klastrowych w zaczynie cementowym modyfikowanym mikrokrzemionka, Budownictwo i Architektura, 2015, 14(4), 117-127.

[8] Wang J.Y., Soens H., Verstraete W., De Belie N., Self-healing concrete by use of microencapsulated bacterial spores, Cement and Concrete Research, 2014, 56, 139-152. 